\title{
Coming to terms with dysfunctional hybridity: A conversation with Andrew Chadwick on the challenges to liberal democracy in the second-wave networked era
}

\author{
Adrienne Russell, University of Washington, Department of Communication, USA \\ adruss@uw.edu
}

\begin{abstract}
Andrew Chadwick's view of today's "hybrid media system," as outlined first in his 2013 book of the same name, has moved scholars to understand how changes in politics are linked to changes in communication infrastructures and tools and to the ways people negotiate power in the networked media environment. His work has provided readers with a blueprint to follow that moves focus beyond the usual categories of media and the usual sites of power. In this interview, conducted in November, 2019, Chadwick discusses what he calls "dysfunctional hybridity" and the urgency that kind of hybridity brings to the need to update our thinking about media, power and society.
\end{abstract}

\section{Keywords}

dysfunctional hybridity, networked journalism, online civic culture, disinformation

Andrew Chadwick's view of today's "hybrid media system," as outlined first in his 2013 book of the same name, has moved scholars to understand how changes in politics are linked to changes in communication infrastructures and tools and to the ways people negotiate power in the networked media environment. His work has provided readers with a blueprint to follow that moves focus beyond the usual categories of media and the usual sites of power. In the fall of 2018, just after the publication of the updated second edition of The Hybrid Media System, in which Chadwick responds to Trump-Brexit-era developments, Colin Porlezza and Philip Di Salvo, the editors of this Thematic Section, convened an ECREA pre-conference in Lugano, Switzerland, titled Dissolving Boundaries of Hybrid Journalism, where I saw firsthand the impact of Chadwick's work on the field. Scholars there presented work exploring the role played by bots, whistleblowers, activists, entrepreneurs, among other actors in shaping the structure and content of journalism work. I opened the event with a talk about my 2016 book, Journalism as Activism, which highlights some of the ways media activists adept at using and creating new communication tools are taking up the work of journalists, expanding the field in significant ways and shaping on a new level traditional news stories and genres. I could sense there at the conference a shift in thinking among the participants, away from old categories and assumptions about topics worth studying and where power resides. I also saw the way many of the participating scholars, myself included, are struggling with how to make sense of the darker side of hybridity that has become apparent in recent years. In the interview below, conducted in November, 2019, Chadwick discusses his recent preoccupation with what he calls "dysfunctional hybridity" and about the urgency that kind of hybridity brings to the need to update our thinking about media, power and society.

This conversation has been lightly edited and condensed for publication.

Adrienne Russell: The second edition of "The Hybrid Media System" (2017), your influential book, includes a new chapter on the election of Donald Trump and a compelling discussion of what you call "dysfunctional hybridity," in which the networked media landscape plays host to practices and technologies - fake news, bots, 
hacking, and so on - that contribute to the erosion of democratic norms. Yours is one of the best updates to a lot of frankly very optimistic research and writing, including my own, that emphasized the democratic potential of the networked environment. How did you get there?

Andrew Chadwick: Well, yes, one of the challenges of the hybrid media system framework is that it celebrates and describes the increasing diversity of media-related practices. We can talk about how people share information and about their interventions in the public sphere. We can see how digital media enabled a whole range of different activities that previously weren't possible in the broadcast-dominated media system. But a lot of us missed what I call the dysfunctional aspects of hybridity. The same technological elements of social media platforms, including the way journalists use digital sources for their stories - those elements also newly empower actors whose ideologies conflict with what we understand as the core of liberal democratic societies.

The big dilemma, really, is how to start thinking about the problematic things we've seen over the last three or four years that I would add were always there - but are now surfacing in such concentrated and visible forms. How can we understand, for instance, the role of the hybrid media system in empowering white supremacists, networked misogynists, or racist xenophobes? I think that's what we in the field have missed. We've underplayed the spread of these digitally enabled pathologies. And maybe that's because most researchers, generally speaking, work from a liberal or leftist perspective, which shapes the kinds of things we've looked for. A lot of the literature on social movements and protest using digital media has - not all of it but most of it - cherrypicked examples that are innately progressive. It has tended to ignore examples of activity that aren't progressive. The bigger picture question is: What kind of media system do we really want to put in place to serve liberal democratic societies?
Russell: Which raises many more questions, made more urgent by developments over the past three years. Like, what does the term liberal democracy mean today, given an environment where political institutions are openly laced with corruption and political processes in many cases are breaking down?

Chadwick: I appreciate that the term liberal democracy is deeply problematic, because there are all kinds of arguments about the limitations of that particular model of politics. But I think we need to take a step back and consider that there are certain groups with ideologies that seek to undermine the values of tolerance, of mutual understanding, respect, civility - dare I even use that term? - and that we're living in a time when these kinds of forces are probably more powerful than ever in influencing the public circulation of symbols in politics. I can't remember a time - perhaps the late 1970s when I was only eight or nine years old - when the far right was as active as it is in contemporary British society, and I think much the same could be said about the United States as well as Europe, particularly Eastern Europe.

Equally, I think we've seen, when it comes to the antifeminist movement - the "manosphere," or the various manifestations of networked misogyny online we've witnessed an incredible amount of visibility for these ideas. We always knew they were there, but it's the visibility and the regularity with which they appear in the kinds of networked forms of participation that we now know are hugely important for all types of political activity.

Where I'm coming at this from, really, is to say that, if we look at what we mean by media hybridity, we've got to open up and recognize that many of our theoretical perspectives were hatched only in relation to progressive examples. Think of Lance Bennett and Alexandra Segerberg's work in The Logic of Connective Action (2013) or some of my work before The Hybrid Media System, in which I examined forms of activism largely involving progressive actors trying to contest news frames that were portraying their side in the worst light. 
We didn't train as much attention on the way these dynamics also work to empower forces destructive to liberal democratic norms.

Russell: In addition to playing catch-up on that score, though, there's also a tendency to think and talk and write as if we're in a constant state of change - which is true, we are in a constant state of change - but I'm wondering about how these trends you're talking about, the ones we missed and that we're living with as a powerful force in our lives now, are creating lasting impacts.

Chadwick: I've become increasingly interested in long-term change and how we can get beyond the idea that everything is always and forever in a state of chaos, transition, and turbulence, and start to focus on how norms become embedded. You and I have talked before about how people's expectations about acceptable behavior start to change, in a rather complex and dynamic relationship with technological shifts. We have also talked about the kinds of social cues people now encounter in the media environment. You and I have been researching this field for quite a long time now - 20 years in my case - and I think we've got to start pointing to some of the longer-term shifts in people's norms what I'm calling online civic culture.

Russell: Okay, right, so can you talk a little about online civic culture in relation to Trump and the various cultural and political streams that came together to secure his election. I thought you very effectively took that up in the second edition of "The Hybrid Media System".

Chadwick: Yes, thanks. When it came to the new chapter in the second edition, it took me a long time, and I became obsessed with it, really going into as much depth as I could, within the constraints of a book chapter, albeit a rather long one. I found that one of the most interesting elements of online civic culture in relation to Trump is that it formed through a combination of the activity of both elite actors and ordinary members of the pub- lic. If you think about the role of misinformation and disinformation in our politics now, I think we've got to acknowledge the role played by ordinary social media users, non-elites, in spreading problematic information. But we've also got to be acutely aware of the role elites play in introducing that information into the media environment. And, of course, we have to also be aware of efforts to document and call out such activity.

One example of the latter is Glenn Kessler, who has been the editor and chief writer of The Washington Post's "The Fact Checker" ${ }^{1}$ since 2011. He's produced extraordinary catalogs of the number of interventions that Donald Trump has made just based on lies. Trump made more than 6,000 false and misleading statements in the first two years of his presidency. We've always had partisan bias in media, of course, but if Glenn Kessler and his fact-checking team is saying on the record that they have a catalog of several thousand false utterances, I think we're in a different kind of environment than where we were even ten years ago.

I think there's also something of a broader cultural shift going on, which I'm calling the culture of indeterminacy, which empowers and disempowers people in different ways in different settings. It's become part of the fabric of our politics in a way that I don't think we could have predicted even a short time ago. Whether or not that's likely to change when, if, Trump doesn't win next year, I'm not so sure.

Russell: And it's not an isolated example, of course. How is the culture of indeterminacy playing out in British politics?

Chadwick: Recently, we've seen various manifestations. From the Remain side of the Brexit debate we've had bizarre statements about the amounts of money that supposedly will be available to reinvest in public services and the National Health Service should the UK not leave the EU.

1 Glenn Kessler, Fact Checker: The Truth Behind the Rhetoric, The Washington Post. https://www.washingtonpost.com/news/ fact-checker/wp/category/donald-trump/ 
This is a mirror image of the lies that were told by the Leave campaign during the Brexit referendum. None of these numbers is based in any kind of objective reality.

At the same time, we've also seen an extraordinary BBC investigation into supporters of the Conservative Party behaving in ways that make their social media posts - Facebook posts on Boris Johnson's public page - appear as if they are automated, bot like responses. ${ }^{2}$ The story emerged about three weeks ago. Observers started suspecting that posts appearing on Boris Johnson's page - very short bursts of commentary saying things like "100 percent agree" or "I'm with you, Boris" - were generated by bots. It was a rush to judgment. Fragments of code also started to appear in the messages. So it looked as if it was an automated, scripted intervention that had gone wrong. But it transpired that real people were pretending to be bots. They were deliberately acting like bots to troll critics of Boris Johnson.

Russell: So, the advantage of pretending you're a bot is, like, next level agitation? Bots exacerbate polarization, so humans behaving in bot-like ways is meant to just further piss off the opposition?

Chadwick: This is the thing, right? To goad the other side, to, yes, have a sense of mischief, to irritate the opponents. Looking at the code that was supposed to have been mistakenly introduced, looking at it now, it does look like it has just been pasted in by somebody, because it doesn't look like any code that would be involved in an automated campaign. That struck me as just extraordinary. I've never come across anything like that.

Russell: But it's recognizable now for what it is - a contemporary media practice. But it's also the kind of thing that points to a broader cultural shift in how politics is playing out, among elites, among everyday people, right? What's it telling us?

2 Joey D'Urso, "The real people pretending to be 'Boris bots' on Facebook," $B B C, 1$ November, 2019. https://www.bbc.com/news/ blogs-trending-50218615
Chadwick: It's obviously an extreme example, but what this brings home is the unexpected affordances that social media environments now provide for inauthentic behavior. The game isn't just about automated, inauthentic accounts. That whole scene has become implicated in a much broader scene of trolling and of so-called "playfulness." Not the kind of playfulness that people were celebrating in the early days of social media, or, going back even further, the idea of playfulness around digital identity in the late 1990s - not that but a disruptive, chaotic, destabilizing impulse.

There's this 2018 American Political Science Association conference paper by political psychologists Michael Bang Petersen, Mathias Osmundsen, and Kevin Arceneaux, where they talk about the need for chaos as a motivator for people who spread false information, conspiracy theories and rumors on social media. I think that there's something in that. They did surveys in the US and Denmark. There is a group - it's a minority, but it's a substantial minority of people (they estimated these attitudes are present in up to 40 percent of the US population) - that now see the media environment as an opportunity to destabilize and to behave in ways that amount to giving the finger-stick to political elites of various kinds - and indeed to the whole rationality of the political process. To some extent it's a manifestation of the way the hybrid media system can enable these very rapid, real-time interventions in political discourse in ways that weren't possible before.

Russell: So, what are the implications of these interventions - sometimes carefully orchestrated but other times spontaneous and grassroots?

Chadwick: Mass publics now use social media to send signals to others who might think "I wouldn't mind doing some of that. I'm on the side of people who want to cause a bit of trouble, a bit of mischief, and I've got reasons for doing it and opportunities too". The reasons people have for doing it - that's the hard part. How we 
dig into those motivations - and they're likely to be extremely complicated - that's a big challenge for researchers. But if we think about the mere existence of the need for chaos, in days gone by, we might have said, "Well, it's great. It's playfulness. There's too much constraint in the public sphere" because we'd look at the broadcast media system and think ordinary people don't have a say and it's top-down and controlled. Think about when TV became really important in politics from the $1960 \mathrm{~s}$ onwards. Well, by the late 1990s, the literature in political communication was full of pessimistic assessments of alienation from the media, alienation from the political process, apathy, disengagement, as a result of the broadcast media system.

But then the Internet comes along and everybody thinks "Oh, it's going to be so different. People will get empowered. We're going to see voices in the public sphere. We're going to see pluralism on a scale that we haven't seen before."

All of that happened, but what we underestimated was that this pluralism also enables these kinds of democratically dysfunctional behaviors that we need to keep an eye on. That's been the agenda since 2016. There's a whole range of interesting research coming out now and a lot of younger scholars are fired up by this agenda as well.

Russell: There are all kinds of related implications. At the level of online civic culture, norms are changing, and there is an expansion of ways for people who are disgruntled to express themselves, in playful ways and in frightening ways, and so on. Meantime, at the level of elite strategizing, we have seen an industry emerge around developing purposeful interventions into the system to disrupt, misinform, and create chaos. Given that it may not be a characteristic confined in the media system to a moment of transition, but rather one that might already be embedded, how do scholars approach these shifted practices?

Chadwick: On the level of documenting it, I don't have any kind of huge methodological plan that I want to lay out and say that that's the correct way. There's some excellent work emerging. Kate Starbird and Emma Spiro, for instance, at the University of Washington, are doing some interesting big data-driven analysis. ${ }^{3}$ There's been some great experimental literature in the field driven by political psychology and political communication researchers such as Jason Reifler, Adam Berinsky, and Brendan Nyhan. That's useful, in part, because it's very controlled and strict in its models of causality, but it doesn't say a great deal about the specifics of social media environments and the particular technological designs that shape and constrain the ways people behave. I would also say that science and technology studies has been a bit slow to react to the post-2016 shift.

Surveys are also useful. That's something we've focused on at the Online Civic Culture Centre (O3C) ${ }^{4}$ at my university (Loughborough) because we were lucky enough to partner with a survey company, Opinium Research. What was notable about the data we found in a nationallyrepresentative survey from late 2018, which we published in our report in the spring of 2019, is that 43 percent of news sharers on UK social media share inaccurate or false news. Seventeen percent knowingly share news they thought was made up when they shared it. It's not a nuanced or complex finding, but it does help establish just how prevalent and widespread is the behavior. We received quite a lot of feedback on that finding - "Are you sure?" "Yes, we're sure," we said.

Russell: That's a standout statistic, especially because it's difficult for many of us to imagine being part of that particular problem.

3 See, for example, Kate Starbird, Dharma Dailey, Owla Mohamed, Gina Lee, and Emma S. Spiro, "Engage Early, Correct More: How Journalists Participate in False Rumors Online during Crisis Events." In Proceedings of the 2018 CHI Conference on Human Factors in Computing Systems, p. 105. ACM, 2018.

4 Online Civic Culture Centre. https://www. lboro.ac.uk/research/online-civic-culturecentre/ 
Chadwick: The underlying reasons for these numbers are very, very difficult to identify, but just as a simple description, it helps put the problem on the agenda. I'm currently working on designing a more in-depth, longitudinal, qualitative, interview-based study. It's to try to understand in a much more contextual and relational way why it is that false and misleading information has come to have the kind of social and political utility it does, both online and in local communities.

The media literacy debate went a little stale, but it's reemerging powerfully. The number of events that I've been to over the last three years where media literacy has been raised as a panacea for all of the world's ills, I can't tell you - but then little gets done about it in relation to online misinformation. One of the interesting things with the media literacy debate is that, as computers became more important and digital media became more important, the debate became much narrower. It often became a debate about digital skills and how to teach people how to use websites, how to buy stuff online, and how to apply for a passport or Medicare or whatever. I know critics such as danah boyd have argued that media literacy may have backfired because it fostered a culture of cynicism toward media. ${ }^{5}$ But I'm not so sure about whether that applies in all contexts. One thing that certainly has happened is that digital literacy has become very narrowly defined. There are people who have continuously pushed against this, such as Sonia Livingstone (2004), for instance.

I think there's something in the idea that we can go into people's socially situated daily lives and find out a lot more about their motivations for sharing problematic information. What is missing at this point is a richer, more contextual understanding of the role that information plays in people's everyday lives and how it gains and loses social utility for specific groups of people. That process is also tied to the question of identity. We already know that

5 See, for example, danah boyd, "Did Media Literacy Backfire?” Data \& Society, 5 January, 2017. https://points.datasociety.net/didmedia-literacy-backfire-7418c084d88d strong partisans tend to believe information that presents their side in a good light. We know about motivated reasoning, whereby people justify to themselves, often using very elaborate methods, their pre-existing prejudices and false beliefs. They will have those in mind as they are exposed to media content. But we know much less about what goes into the decision to share content. That's what we've tried to focus on here at $\mathrm{O} 3 \mathrm{C}$ - the ingredients that go into the share. But we know very little right now, and I don't think we're likely to learn everything about the ingredients that make the share from large- $\mathrm{N}$ studies and descriptive, big data studies.

One way we plan instead to study this is by asking subjects to take out their phones and talk through the problematic pieces of information that figure in their everyday lives in a detailed, contextual way, where one recognizes that there's reflexivity in the interview process. We won't be able to generalize to the population, but then we might have much more refined and interesting variables to explore in broader survey-based studies. This is not to say that qualitative work is superior to general survey-based research; they complement each other.

Russell: Right, getting a closeup view of how people are actually engaging with the material can help know what questions to ask. It's interesting that you're focusing on the media habits of individuals. Can you elaborate? Why might it be more interesting to look at individual practices rather than at things like the kind of technology people are using or technology policy?

Chadwick: On the issue of people-versus-technologies, I've just never seen it like that. I'm heavily influenced by Latour and the ideas of actor-network theory. I'm not the only one, of course. There was a whole wave in that late-2000s moment, lots of interesting ideas floating around about the interactions between technologies and humans and their mutually constitutive roles as actants. I've always been influenced by that particular perspective. When I talk about the hybrid media sys- 
tem, that does include technologies and people and all of the interactions between them. What I don't subscribe to, though, is the idea that it necessarily means that you're being technologically determinist. I dislike that term, and it's become a lazy critique of a lot of work, including Latour's as well. The reality is that we are shaped by our interactions with technologies. We're not fully determined by them. The technological environments within which we behave play a role in shaping our behavior, and I'm completely unashamed about saying that. That's not to say that they determine everything in the first or last instance, but they play a role.

When I'm talking about individuals, I'm talking about the need to understand how individuals are socially situated, but also technologically situated as well. Again, I'm not the only person. Look at the new outpouring of work on algorithms, such as Taina Bucher's great book If... Then, which came out last year. (Disclosure: the book is published in the Oxford University Press series I edit). It's this idea that it's not a binary either/or when it comes to media technologies and social practices. You've got to look at people in their socially situated context. Part of that socially situated context is a technological context. When people are interacting online, the news feed, it's the ways that's algorithmically curated - ways that, as we know from surveys, many members of the public just don't fully understand. Of course, academic researchers don't fully understand it either, because we don't have access to whatever "secret sauce" makes the algorithms.

When I'm talking about these longterm shifts in online civic culture, those are partly technologically shaped, and they're about the moments of interaction between humans and technologies. It's that dialectic that drives the whole process forward. I'm not saying that there's something called culture, which is innate and intrinsic in human brains, if you will, that then acts as a force in the world. What I'm saying is that these complex social and technological variables, and the ways humans behave over time, lead to changes in expectations about what's seen as ac- ceptable and not acceptable in the public sphere. That's the biggest normative concern I've got with online civic culture - that there are large numbers of people now who are seen as willing to engage in behaviors that are problematic for liberal democratic societies. Does that answer your question about a system-versus-individual focus?

Russell: It does. What about the part about the elite forces, not the everyday people, that are shaping the system in "democratically dysfunctional" ways? How do we deal with that?

Chadwick: That is, in some ways, a more tractable problem than the problem of digital literacies. That said, it requires some kind of political intervention.

We're now in a situation where the idea of the social media company as platform, if you start deconstructing it, it's more and more bizarre. I think Tarleton Gillespie's work has been very valuable on this. You've got these metaphors used by Google, Facebook, Twitter of providing a stage on which others act. The original model is that they don't take much responsibility for the ways in which people act, that they're just providing a stage, a platform. That model is now almost dead. We're actually seeing the dying days of it play out. It won't be as quick a death or even the same kind of death, maybe, in the United States as it will in, say, Western Europe. For example, we've seen the signs of that just this week, with scholars having a real argument on Twitter about freedom of speech and "freedom of reach" after Facebook began insisting that it won't regulate political ads the way that Twitter has said it will.

There's a peculiarly US perspective on these things. Liberal-left US scholars are arguing that it's wrong to outlaw political advertising on Twitter because that will create jurisdictional problems and erode the anti-Trump movement. Also, that it will deny speech and reach to progressive movements as well because they want to advertise online and inform the public.

It's really hard to decide what's political, and what isn't, and of course, that problem is not going to go away. The Brit- 
ish perspective on these things is very different because historically, we've long had regulation of advertising in elections. We don't have political advertising on broadcast media. That's why, when we in the UK see so much campaign advertising on UK social media, it looks like a crazy Wild West scenario. British scholars have been far more reticent about participating in the debate about Twitter's banning of political ads because we recognize that there are many, many reasons why you would want to regulate political advertising, not least because there are inequalities between different providers of ads. If you go back to the early 2000s and the McCain-Feingold Act on campaign finance in the United States, one of the Democrats' major concerns was that the Republicans would always outspend them using soft money, because wealthy donors would always tend to favor the Republicans.

It is strange that we're seeing these kinds of ideas recur, but the current changes in the media environment are challenging us all. The established terms of debate have quickly started to dissolve.

Coming back to your original question about what kinds of interventions are required, I think that it's always going to be a mix of government regulation and self-regulation by the platform companies themselves. But that self-regulation doesn't come about by accident or just out of the goodness of their hearts; it comes from real political pressure, including from policymakers, to clean up the Internet. If we've got an environment where it's easy for political elites to circulate prejudice, falsehoods, all kinds of inaccurate information strategically released to divide communities and to pit one community against another, whether it's religious or racial, we need to tackle the problem. We have to take sides and say, "There are things we need to do to make sure that social media environments are making good contributions to civic culture rather than eroding or undermining our civic culture."

I think that that's where we are right now, though I recognize that is a bizarre generalization because there are countries where there is no genuine freedom of speech on social media. But thinking about the US and the European context, that's where the debate is happening. This means regulation. It will be different in different countries, but I can't see any reason why we shouldn't look at some form of regulation as a positive outcome.

Russell: Yes, I agree. On that score, how do you perceive the news coverage of the dysfunctions we've been discussing? Even as recently as 2016, there was very little mainstream coverage of technology's role in politics and strategic political communication, the relationship between the data industries and democracy, of micro-targeting publics and misinformation - on so many of the things academics have been studying. Cambridge Analytica was a shock to the press and to the public, but not so much to academics. Now the coverage seems to be getting more thorough. The BBC investigation into the fake bot posts, you just mentioned, the recent investigative section of the New York Times performing a data analysis of Trump's tweets. ${ }^{6}$ Some journalism outlets are recognizing how central the story of technology is to politics and public life. But this is of course complicated by the fact that there's a decrease in trust in these press outlets. What's the proper role for journalism and a realistic expectation of how effective journalism can be in exposing and educating people about "dysfunctional hybridity"?

Chadwick: The first thing I'd like to say is that the ways in which journalism has evolved means journalists are implicated in the current crisis on a number of levels. Some of it is just part of the pressure of having to adapt to a hyper-competitive media environment where the number of new actors - not all of them survived but still, if you think about the likes of BuzzFeed, the likes of Vice - it's just a much more complicated environment in which to be a professional elite journalist now than it was even ten years ago. If you think

6 See "The Twitter Presidency," New York Times, 2 Nov. 2019. https://www.nytimes. com/interactive/2019/11/02/us/politics / trump-twitter-presidency.html 
back twenty years, it's a completely different situation. A lot of the pressure is being created by the need to compete.

The reality is that journalists themselves are implicated in the obsession with breaking news, the obsession with social media metrics, the obsession with Trump's latest tweets at what time of the day or night and how many likes or retweets they get.

As I've shown in The Hybrid Media System, journalists have embedded social media into their working practices, not just at the level of sourcing. In other words, there are literally journalists, and you know this, of course, whose beat is to sit and look at social media screens, dashboards unfolding all day long. It's not just about that. It's also that the texture of news stories and the actual presentation of facts in the world now relies upon social media discourse. This is what Trump recognized in 2015, actually, long before the election campaign properly got underway. He recognized it really early on.

There were a few people who pointed this out, but few were paying attention. Then all of a sudden, as soon as he was elected, it was, "Let's go back and look at Donald Trump's tweets," and, "Oh, yes, we saw it all along."

Quite a few saw it happening during the campaign and thought, What's going on here? One of the longstanding arguments about political campaigns is that they can use social media to bypass traditional media. This was said in the days back in 2004, 2006, and 2008, when we saw email come into its own as a campaign medium. The argument was, "They're going to bypass traditional media and reach the public. They're going to reach their partners and supporters and we won't know anything about it." What we didn't understand back then (and this is part of the hybrid media system framework) is that it's not just about bypassing; it's about influencing. Trump's approach was not about bypassing mainstream media; it was about using social media to influence mainstream media. That's become almost a truism in the last couple of years, but in 2016, there weren't many people saying that. In the book, I tried to show how this happened. One fascinating thing here is how social media have enabled the signaling of transgression. Trump was, and still is, "good" at transgressing norms. By that I mean the traditional norms that we would expect presidential candidates to adhere to, he just deliberately rips those up in order to generate attention. Boris Johnson in the 2019 UK campaign has used the same strategy.

It's almost like the old cliché, “There's no such thing as negative publicity." In the second edition of The Hybrid Media System, I noted that we're now in a media system where attention is such a valuable resource, that there are so many opportunities for you as an individual to devote your attention to so many different types of content, that actually grabbing attention in that old way, but with new methods, has become much more important. Distortion in the economy of attention in the public sphere is something we're only just really coming to grips with.

This is an important part of what Trump was doing in 2016. It's become a characteristic in general of strategic campaigners who want to try and grab attention, even if only very fleetingly, for their particular cause. There's this mythology that built up in the 2016 campaign about whether or not journalists were taking Trump seriously enough and the pitfalls of doing so. They face a similar issue when it comes to ideas that are destructive of liberal democracy as well. Extreme misogyny, white supremacy, misinformation - how do you report these things while drawing attention to them in a way that shows that they are transgressions of norms that ought not to be transgressed in a liberal democratic society? How do you do that in a way that doesn't risk you just simply spreading the word? This is a major problem.

One of the things that's become fascinating again is thinking about norms and the long-term reshaping of people's behavior. We know, going back to social psychology studies of the diffusion of rumors, for instance, all the way back to the Second World War, is that what the social psychologists call fluency is a an important 
determinant of how people come to hold false beliefs.

The disturbing thing about fluency and again, this rests on all of the repetition and circulation affordances that we've all celebrated as being so beneficial about social media - the reality is that simple repetition and recirculation exposes larger numbers of people to problematic information. Even if that information is deeply false, it still enhances a sense of ease or fluency with the information. Fluency leads to credulity. The more fluent you are, in other words, the more you've been exposed to a particular piece of information, even if it's false, the more likely you are to believe it.

It's a major problem for how journalists report. Perhaps we're now seeing journalists fighting back and coming out the other side, certainly in the big professional media organizations, such as The Washington Post and the New York Times. We're starting to see signs now of a much more savvy approach to social media as a source for stories. I'll just park this thought for now, but what we also need to recognize is that there are many, many cash-strapped news organizations that don't get the chance to make this decision. They are, by necessity, deeply implicated in writing and thus amplifying stories about viral YouTube videos, or outrageous tweets. There's some interesting research now coming out in journalism studies that speaks to the new reality of the local newsroom. When I say that some news organizations are getting more savvy, I think that's the elite-of-the-elite organizations, and also the well-funded ones, as well. We mustn't forget the political economy of this, because the Washington Post is now far better resourced than it was before Jeff Bezos bought it.

So, yes, journalists are implicated in the current crisis, but I also think that it's not just about the structure of the news industry. It's a deeper problem of the social psychology of behavior online. I've become more and more interested in the individual, psychological roots of people's behavior, the behavioral tradition in psychology: flocking behavior, herding be- havior, cueing, fluency, why people come to act on informational cues in ways that don't seem to be perfectly rational. Well, they're partly explained by the social-cuing contexts of our behavior. When you throw technological affordances into that mix as well, that makes it even more complicated.

When journalists produce news, part of the problem is that they're now in an environment where other people's behavior and the likelihood of recirculation of a story is important and plays a role in what gets written about. Journalists might not have a full awareness of the limitations on the rationality of that environment. We need to understand far more about what shapes and constrains rationality in the public sphere, not least because social media discourse goes constantly circuits back into professional journalism. This is a hybrid media system problem, but I didn't have anything to say about rationality in the book.

Russell: It makes a lot of sense to think about the social psychology aspect given the issues about which people have very different perceptions - the seemingly increasing areas of irreconcilable differences. I've been thinking a lot, for example, about climate communication and about why there is so much discussion and effort around getting the right information or the right amount of information, even though people who doubt and deny climate change continue to do so despite the flow of excellent reporting. The idea of fluency, that's actually very helpful in thinking about these matters. Couldn't the solution to disinformation be simply working to interrupt fluency?

Chadwick: Yes, the solution is to interrupt fluency. But then there's also motivated reasoning. Therefore, even if you're interrupting the environment in which fluency can occur, you're never fully going to get beyond people's prejudices and preconceived biases. My problem with all of this, as a communication and media scholar, is where did these biases come from in the first place? This is one of the things that's bedeviled our field, hasn't it? You look at 
the historical debates: strong effects versus weak effects. There's been a real reluctance on the part of many communication and media researchers to talk about media effects. There has to be a renewed conversation now about where norms and behavior actually derive from in the first place and how they become embedded over time.

I'm a fan of Mark Deuze's idea in his book Media Life, that we live in media, as fish live in water. There's a lot to be said for that perspective. Of course, the mechanistic traditions of some quantitative social science finds that difficult to fathom, because information is theorized as something that is fully exogenous and operates as a force upon us.

We need to understand that people's perceptions of the world are built up through many complex but often very short-term interactions that accrete over time. I think accretion is a good word in this regard. As things accrete over time, you can see that it's phony, in a way, to say, "If only we could introduce, in a one-off setting, correct information about how to see climate change."

I keep coming back to this idea of a relational perspective on digital literacies, and I deliberately use the plural term, literacies, because I don't think we'll reach a stage where there is a singular, universal state of being digitally literate. We need to understand how different types of information have different forms of social utility in specific community, familial, social, and cultural contexts. This is the lesson of some of the qualitative work that's emerging. Think about Arlie Russell Hochschild's book, Strangers in Their Own Land, Kathy Cramer's work on rural politics in Wisconsin, which both show how people develop narratives of how to make sense of the world. For them, these narratives, or deep stories as Hochschild calls them, have real purpose, and it's about getting into those moments, trying to develop long-term educational interventions that make a difference to how people see others who are unlike themselves.

It's not simply about balancing opinion as well. That's been a trend in the media literacy literature going back thirty years - if only we could get people to weigh up the arguments on both sides, the argument runs. I'm not sure that that's going to work. We have plenty of opportunities for people to learn online about different perspectives on the world, but do these have utility for people in their everyday lives in their communities? For many people, it's not a simple question of saying, "I'm going to go online and learn about all of the different sides of the story" - not least because it becomes really exhausting to do that.

To come back to the role of news, journalists might need a much richer understanding of the kinds of information that people find useful in their communities and how they can intervene in those contexts to create information that empowers people with the truth. I don't think journalists should just give up and say, "Everything's post truth. There's indeterminacy everywhere. We can't make a difference. Let's just follow the dollars." There are some newsrooms that may think like that, but journalism must retain its public mission to enlighten citizens. It's a question of finding the truthful information that citizens need in order to become empowered.

Russell: Conversely, what sorts of information is disempowering, not only for the individual but for various groups?

Chadwick: Good question. Take, for example, Urban Dictionary, which has been a fascination of mine for a long time now. I spoke about this at some length in a talk I gave at the Reuters Institute at Oxford in 2018. My 11 year old daughter sometimes searches Google for stuff like language use, special terms, definitions, all sorts of slang, so I see this on a personal level. Now, I know that street slang evolves very quickly - absolutely. But Urban Dictionary is bizarre. It's mixture of misogyny, racism, casual insults against all sorts of different religious communities, stuff that's just made up, stuff that has no basis and terms that are clearly not used by people in everyday life. But this great piece just came out in New Media \& Society by communication and media scholars Debbie Ging, Theodore Lynn, and Pierangelo Ro- 
sati at Dublin City University. It just hit on the head what I was struggling with when trying to present last year at Reuters (to frowning faces) about why I think Urban Dictionary is a problem. (Incidentally, I dug into the economics of the site and how it's funded through ads it sells through the Google Ad Exchange network and how it makes its money. It's quite a lucrative website, often in the top-500 Alexa rankings in the world. It's seriously big, with 180 million monthly page views, mostly clicked via Google search.)

Interestingly, given the mixed economy or the division of labor, however we might want to describe it, in content creation and linking in the online space, what Ging and her colleagues argue is that Urban Dictionary entries are hijacked by the manosphere online, who, after all, have their own mixed economy of content based around their own wikis and forums. Again, these are things that we used to celebrate about Web 2.0. We thought, It's good. It's empowering lots of people. Well, yes, it's empowering extreme misogynists as well. So the lexicon of the manosphere gets encoded into the entries in Urban Dictionary, and then people do searches on Google, and the economy of attention has already been hijacked because Google is prioritizing Urban Dictionary in its search results. The implication of Ging's and her colleagues' article is that we need to be much more strategic about examining these interconnections between online content - the divisions of labor between news and journalism, search engines and rankings, retweets, shares, likes, how all of that goes together in ways that can skew the information environment for people who are looking for particular types of information at particular moments.

Recently, Michael Golebiewski and danah boyd at Data \& Society released a new report about data voids. I don't know if you've seen this - ?

Russell: Yes, it's about how data voids, or searches that turn up little to no results, are seen as opportunities by people looking to manipulate the information environment and so fill those voids with misinformation.
Chadwick: Right. That really struck a chord. This is something we need to pay much more attention to - and I think journalists in particular should be aware of how this works. Journalists can make a difference because many have the power to introduce information into the public sphere, which will get highly ranked by Google, and prioritized in search. It may also get prioritized in social media feeds if what the social media companies say about prioritizing reputable sources and curating feeds with human intervention actually happens and makes a difference. Facebook's record has been patchy in that regard, lately.

Take, for example, the issue of climate change or science communication more broadly: these areas are problematic as well because much of the scientific literature doesn't get returned in regular Google searches. Even if it did, would it be accessible to the average member of the public? Probably not. Again, that places a huge responsibility on journalists to introduce high-quality information into the public realm, in the knowledge (or perhaps hope) that, in turn, it will have an influence on search rankings and ultimately determine people's ability to find good information. It's probably time we moved away from this notion that the Internet is all about social media news feeds or all about news organizations' websites, and toward the assumption that there's actually a complicated division of labor when it comes to the production and consumption of online information.

Russell: Point well taken - and I'm not sure how Google has managed to sidestep so many of these debates. It's a messy complicated set of realities, and one that's only going to grow more complicated. But if we start taking a more holistic view of the problems and of the solutions, along the lines that you're talking about, we'll be better prepared. I keep thinking the main institutions of democratic society have just been so reactive, or less than reactive - which I think is what has people terrified about the era of widespread deepfakes, which seems like it's days away at this point. 
Chadwick: Yes, Cristian Vaccari and I have a project underway here at O3C on deepfakes, on which Cristian is leading. The first disturbing thing about deepfake video comes from what we know about individuals and how they process information. We know from experimental research that individuals are more likely to recall video and image content than they are textual content. That was demonstrated in experimental settings long before digital media emerged.

On the other hand, we spend a long time in communication and media research examining the active audience and in understanding how people make sense and interrogate the nature of media content. People adapt their expectations over time to what's factual and what's fictional. It's really fascinating. Take, for example, early cinema. When cinema was introduced in the 1890s, people would go into movie theaters and be astonished and sometimes scared out of their wits. Some people were terrorized by images they'd never seen before. A good example is when, in 1895, the Lumière brothers screened their short film "L'Arrivée d'un Train en Gare de La Ciotat» ("Arrival of a Train at La Ciotat Station"). But people soon adapt. Special effects in Hollywood, the line between fact and fiction: humans are really good at making that distinction.

The problem with deepfake video is that it's fabricated nonfiction. It's not fictional content and it's not wholly about entertainment. Imagine a viral video deepfake of, say, a politician or perhaps more likely, a newsreader or a reporter that isn't particularly well known, speaking in a mocked-up studio news environment. The problem is that it's so perfectly executed and the representation is so convincing. If we think about this, it throws into jeopardy some of these preconceived ideas we have about the active audience and our ability to decode political bias.

Add into that mix the rapid-fire nature of exposure to these videos and the ways people seem to be very comfortable now in spreading information (in ways that researchers didn't foresee) very, very quickly, even if they haven't interrogated it. Shar- ing without adequately reflecting upon the content or checking it, the desire to fit in, the excitement, the thrill of participating in the news cycle. All of these things are important and need to be brought into the analytical mix as well. That's the problem of deepfake video: it speaks to an environment where the kinds of expectations that we used to have about how audiences critically interrogate content become somewhat unsettled. How can audiences contextualize a deepfake video of a politician or a journalist when the deepfake has been created by deep learning AI scripts that actually draw upon the other publicly available representations of that person that are online?

It's a dystopian version of intertextuality, in which the deepfake video is itself fabricated from existing publicly available video, audio, and still images of a person that already exist in the public realm. The idea that we can get to the bottom of it is problematic... You see what I'm saying?

Russell: Yeah, it's sort of, for now, not really fiction; it's fabricated reality. It's the real person in a real setting that that real person really exists in a lot of the time - a news-show set, a stump speech stage, on the floor of Congress, whatever. So it demands a new digital literacy to detect it as quicklyor more quickly - than the time it would take your impulse to share to spur you to act! The mechanisms are so sophisticated that you can't anticipate that they would be factoring into what you're witnessing. At least at first, in the first-wave deepfake era, you're not properly, instinctively on guard.

Chadwick: Logically, it's problematic because there's no obviously discernible $u n$ derneath, below the surface, due to how the technology seems to be developing. I don't really have any good answers to this one. That's why I think regulation is actually really important in the sphere of deepfakes, and I think the platforms themselves have started to realize this as well. I mean, Zuckerberg came out with it last week, where he said, "Deepfakes are a problem." Jack Dorsey, one of the founders of Twitter, explicitly mentioned the 
problem of deepfakes in his tweets when he was talking about Twitter's decision to ban political advertising. It's that sense of not being able to get beyond the surface to, I don't know, factcheck. It is more difficult to factcheck a deepfake when the deepfake itself has been made from resources in the public domain.

This presents liberal democracies with a major challenge. The biggest long-term problem with a culture of indeterminacy is the lack of trust that emerges from it. If it becomes hugely exhausting trying to make sense of this environment, and if there's a realization that the old tools of fact-checking and responsible journalism will work only some of the time and a lot of the time will be compromised, then we could be in trouble. One of the problems is that it opens up space for authoritarian leaders to say, "I'm going to restore order," and we could then end up with regulation of media that is draconian.

On the other hand, the other problem is that people withdraw into the private sphere and they think, "Politics is not for me. That's the public realm. It's crazy." Then I think we could be in trouble.

Russell: That's a very optimistic statement you just made, I think. "We could be in trouble" you said. That means we could not be in trouble, too! I'm pretty sure we're in trouble.

Chadwick: If we just let these forces have free rein, then liberal democracies could be in trouble in the longer term, because the cultural effects over time could be damaging. It's not just a question of people actively participating in spreading illiberal ideas. It's also that people will withdraw into their private sphere and say, “This isn't for me.” Dissident critiques of propaganda in the Soviet Union and the former Eastern Bloc states discussed this. Much of the emphasis in propaganda studies has been on persuasion, influence, and deception, or how it leads people to adopt false beliefs. But one of the real problems of propaganda in the Eastern European context - if you read dissident-turned president Vaclav Havel on Czechoslovakia in the 1970s - one of the problems was withdrawal. People just think, Well, I'm going to stay out of public life and I'm not going to get involved. It just becomes too difficult and I think that's a real problem that we might face if indeterminacy becomes widespread. Hannah Arendt, in her writing about the nature of totalitarianism also raised this problem. This is much more damaging, and just as damaging as the argument that harassment and intimidation silences people. It's related. The alt-right are very aware, when they organize concerted harassment attacks on feminists or people of color, they know what they're doing. It's not just that they're trying to spread the word about their ideas. They're also trying to silence their targets, get them to withdraw into the private sphere.

Russell: Whitney Phillips (2019) recently wrote a fascinating piece published in Social Media+Society that interrogates the influence of subcultural trolling and what she calls exclusionary laughter. In it she argues that mainstream culture has played a key role in normalizing cultures of hate by allowing their expressions to be amplified under the guise of humor without considering the impact that amplification has on groups who are their direct targets. Relatedly, Mike Ananny $(2017,2018)$ has been writing about listening and the role networked press systems can and ought to play in ensuring certain stories, groups, voices don't become eclipsed by all of the noise. It's really key for us to be paying attention to what kind of people are most likely to withdraw and based on what kind of factors. And what kind of changes would prevent that kind of exodus? You can imagine the network splitting into neighborhoods, some clean and neat, more civil, more informed, but also more constrained and expensive, others more expressive but also cluttered with ads and hateful trolling. On some level you can see the momentum for that kind of thing already building.

Chadwick: I agree. Again, it comes back to this idea that the media environment now is very different from the one that prevailed 20 years ago. Media today are not 
just about communication; they're about organization. If you think back to the early debates about digital media and politics in the 2000s when Bruce Bimber, Lance Bennett, Dave Karpf, myself and others were theorizing how digital media may spur organizational change - one of the strands of the hybrid media system framework. You can also apply these ideas now to the issue of silencing and marginalization online. When white supremacists and misogynists mobilize harassment in a distributed network environment, they are using media as a means to force organizational change upon their opponents. The organizational outcome in this case is silencing and demobilization of those opponents. When women see other women being harassed online they are more likely to think "I'm a woman. I'm a feminist but I don't want to be out there in the public realm because I don't want to be attacked. I don't want to be doxed. I don't want my personal data put all over the Internet. I don't want people creating pornographic deepfake videos of me."

This, again, is a democratically dysfunctional outcome of the communication-as-organization idea that was so important when social media were new, a decade ago. And now, more than ever, we can learn from the insights of that work but recalibrate them for a new era. We again need to go beyond the idea that digital media are solely about the transmission of messages or representations, and instead focus on how they have become central to all types of formal and informal organizational power.

\section{References}

Ananny, M. (2017). The whitespace press: Designing meaningful absences into networked news. In P. J. Boczkowski \& C. W. Anderson (Eds.), Remaking the news: Essays on the future of journalism scholarship in the digital age (pp. 129-146). Cambridge, MA: MIT Press.

Ananny, M. (2018). Networked press freedom: Creating infrastructures for a public right to hear. Cambridge: MIT Press.
Arendt, H. (1973). The origins of totalitarianism. New York: Harcourt, Brace, Jovanovich.

Bennett, L. \& Segerberg, A. (2013). The logic of connective action: Digital media and the personalization of contentious politics. New York: Cambridge University Press.

Bucher, T. (2018). If ... then: Algorithmic power and politics. New York: Oxford University Press.

Chadwick, A. (2017). The hybrid media system: Politics and power, $2^{\text {nd }}$ edition, New York: Oxford University Press.

Cramer, K. (2016). The politics of resentment: Rural consciousness in Wisconsin and the rise of Scott Walker. Chicago: University of Chicago Press.

Deuze, M. (2012). Media life. Cambridge: Polity. Ging, D., Lynn, T., \& Rosati, P. (2019). Neologising misogyny: Urban Dictionary's folksonomies of sexual abuse. New Media \& Society. doi:10.1177/1461444819870306

Golebiewski, M. \& boyd, d. (2019). Data voids: Where missing data can easily be exploited. Data \& Society. https:// datasociety.net/output/data-voids/

Hochschild, A. R. (2018). Strangers in their own land: Anger and mourning on the American right. New York: New Press.

Latour, B. (2005). Reassembling the social: An introduction to actor-network-theory. London: Oxford University Press.

Livingstone, S. (2004). Media literacy and the challenge of new information and communication technologies. The Communication Review 7(1), 3-14.

Petersen, M.B., Osmundsen, M. \& Arceneaux, K. (2018). A need for chaos and the sharing of hostile political rumors in advanced democracies, American Political Science Association conference paper. https:// psyarxiv.com/6m4ts/

Phillips, W. (2019). It wasn't just the trolls: Early Internet culture, "fun," and the fires of exclusionary laughter. Social Media+ Society. doi:10.1177/2056305119849493

Russell, A (2016). Journalism as activism: Recoding media power. Cambridge: Polity. 